\title{
Numerical Experiments on Effect of Topographical Slope Changes in the Dynamics of Landslide Generated Water Waves and Submarine Mass Flows
}

\author{
J. Kafle ${ }^{1}$, P. Kattel ${ }^{2 \dagger}$, P. R. Pokhrel ${ }^{3}$ and K. B. Khattri ${ }^{4}$ \\ ${ }^{1}$ Central Department of Mathematics, Tribhuvan University, Kathmandu, Nepal \\ ${ }^{2}$ Department of Mathematics, Tri-Chandra Multiple Campus, Tribhuvan University, Kathmandu, Nepal \\ ${ }^{3}$ Department of Mathematics, $R$ R Campus, Tribhuvan University, Kathmandu, Nepal \\ ${ }^{4}$ Department of Mathematics, School of Science, Kathmandu University, Kavre, Nepal
}

†Corresponding Author Email: pkattel526@ gmail.com

(Received April 22, 2020; accepted October 16, 2020)

\begin{abstract}
When gravitational mass flows hit water bodies, they create water waves, called tsunami. The slopes of the mountain flanks surrounding a glacial lake or the slopes of the side walls of artificially constructed reservoirs play important roles in the intensity of splash on landslide impact, amplitudes and propagation speeds of the resulting water waves and possible dam breaching or overspilling of water. The proper analyses of such dynamics are useful for the possible mitigation measures. Here, we apply a general two-phase mass flow model to perform several numerical experiments and present geometrically three-dimensional, high-resolution simulation results for rapidly moving two-phase landslide/debris flow down a plane with varying slopes at its different parts, impacting a fluid reservoir. First, the upstream slope is kept constant; later to make it closer to reality, sudden changes in slopes are imposed one after another at different parts of the topography. The results focus on the effects of the sudden slope changes in the formation and propagation of dynamically different solid- and fluid wave-structures in the reservoir. Results show that steeper upper part of the topography produces more highly intensified tsunami that propagates more longitudinally than the steeper lower part. Thus, steeper upper parts need stronger right coast and steeper lower parts demand stronger side walls in mountain reservoirs to withstand the wave impacts. The results may help for the proper modeling of landslide and debris induced mountain tsunamis in rapidly changing slopes, the dynamics of turbidity currents and sediment transports in fluid reservoirs in high mountain slopes.
\end{abstract}

Keywords: Two-phase mass flows; Submarine landslides; Debris flows; Tsunami; Slope changes.

\section{NOMENCLATURE}

$\begin{array}{lll}\mathrm{A} & \text { mobility number } & \mathrm{m}_{\mathrm{i}_{\mathrm{j}}} \\ \mathrm{b}=\mathrm{b}(\mathrm{x}, \mathrm{y}) & \text { basal topography } & \mathrm{N}_{\mathrm{R}} \\ \mathrm{C}_{\mathrm{DG}} & \text { generalized drag coefficient } & \mathrm{N}_{\mathrm{R}_{\mathrm{A}}} \\ \mathrm{C} & \text { virtual mass coefficient } & \mathrm{P} \\ \mathrm{f} ; \mathrm{s} & \text { fluid phase; solid phase } & \\ \mathbf{f}, \mathrm{g} & \text { vectors of transport fluxes } & \mathrm{p}_{\mathrm{b}_{\mathrm{f}}}, \mathrm{p}_{\mathrm{b}_{\mathrm{s}}} \\ \mathrm{F}, \mathrm{G} & \text { fluid, solid-like drag contributions } & \\ \mathrm{g}^{\mathrm{x}}, \mathrm{g}^{\mathrm{y}}, \mathrm{g}^{\mathrm{z}} & \text { components of gravity } & \mathrm{Re}_{\mathrm{p}} \\ \mathrm{h} & \text { debris flow depth } & \mathrm{S}_{\mathrm{x}_{\mathrm{f}}}, \mathrm{S}_{\mathrm{x}_{\mathrm{s}}}, \mathrm{S}_{\mathrm{y}_{\mathrm{f}}}, \mathrm{S}_{\mathrm{y}_{\mathrm{s}}} \\ \mathrm{h}_{\mathrm{f}}, \mathrm{h}_{\mathrm{s}} & \text { fluid, solid phase depth } & \mathrm{T} \\ \mathrm{H}, \mathrm{L} & \text { typical height, extent of a debris } & \\ \mathrm{K}_{\mathrm{x}}, \mathrm{K}_{\mathrm{y}} & \text { flow } & \mathrm{t} ; \mathrm{x}, \mathrm{y}, \mathrm{z} \\ \mathrm{M} & \text { earth pressure coefficients } & \mathrm{u}_{\mathrm{f}}, \mathrm{u}_{\mathrm{s}}, \mathrm{v}_{\mathrm{f}}, \mathrm{v}_{\mathrm{s}} \\ & \text { a parameter for Reynolds number } & \mathbf{W}\end{array}$

$i=x, y ; j=f$,s fluxes quasi-Reynolds number mobility Reynolds number interpolation parameter for drag effective fluid, solid pressures at base particle Reynolds number source terms vector of conservative variables time; space coordinates velocity components vector of conservative state variables 


$\begin{array}{ll}\mathrm{x}_{\mathrm{b}} & \begin{array}{l}\text { position of bottom of slope } \\ \mathrm{x}_{\mathrm{lc}}\end{array} \\ \alpha_{\mathrm{f}}, \alpha_{\mathrm{s}} & \text { reservoir's left end position } \\ \beta_{\mathrm{x}_{\mathrm{f}}}, \beta_{\mathrm{x}_{\mathrm{s}}}, \beta_{\mathrm{y}_{\mathrm{f}}}, \beta_{\mathrm{y}_{\mathrm{s}}} & \begin{array}{l}\text { lateral hydraulic pressures } \\ \gamma\end{array} \\ \delta, \phi & \begin{array}{l}\text { density ratio } \\ \text { basal, internal friction }\end{array} \\ \varepsilon & \text { angles } \\ & \text { aspect ratio }\end{array}$

\section{INTRODUCTION}

Mass flows in geophysical contexts, like subaerial and submarine landslides and, in particular, debris flows are effectively two-phase flows of solid particles mixed with viscous fluid, and are very important sediment transport mechanisms (Pitman and Le 2005; Pudasaini 2012; Pudasaini 2014; Kafle 2019; Kattel 2019). From the environmental and industrial perspectives, advanced knowledge of the evolutions and dynamics of solid and fluid-phases, in particular, in landslides around coastal areas and particle transport in hydraulic plants is very important to estimate the velocity, kinetic energy, momentum and pressure for adopting the appropriate mitigation strategies (Pudasaini 2014). Submarine or subaqueous landslides are commonly observed as a mass wasting process that constitute one of the most important mechanisms for sediment transport which contribute substantially in shaping landscape margins of coastal regions (Kafle 2019). Although many research works have been focused on evaluating the landslide-induced tsunami generation and risks using statistical methods and empirical formulas, there is a lot yet to be studied about tsunami or water waves and submarine mass flow dynamics, and deposits in hydraulic channels and hydropower plants in mountainous regions employing the physical mathematical models, and robust numerical methods (Kafle 2014; Pudasaini 2014; Kafle 2019).

The big mountain rivers, lakes, glacial lakes, several artificial reservoirs, and also hydro-electric power plants situated at high mountain regions in the world are susceptible for landslide impact potentially creating water waves (Shrestha et al. 2010; Miao et al. 2014). Figure 1, as an example, is a picture of the flood due to the detachment and collapse of the rockice wall in Mt. Annapurna IV and the subsequent landslide and avalanche on May 5, 2012. The fluidized debris flow later turned into a debris flood and mud flow when it plunged into and mixed with the upstream source of the Seti River, Pokhara valley, in Kaski District, Nepal. The flood claimed 71 lives and swept away many houses around the river banks downstream (Kattel 2014). There are some more events in Nepal, e.g., the Jure landslide of August 2, 2014 in the central-north Nepal, and other avalanches and landslides in Mount Langtang and Everest areas triggered by the 2015 Gorkha earthquakes (April 25 and May 12) (Kafle et al. 2016; Kafle 2019). Some other events are 1958

$\begin{array}{ll}\zeta, \zeta_{1}, \zeta_{2} & \text { inclinations of basal topographies } \\ \eta_{\mathrm{f}} & \text { fluid viscosity } \\ \mu=\tan \delta & \text { basal friction coefficient } \\ \xi & \text { vertical distribution of } \\ \rho_{\mathrm{f}}, \rho_{\mathrm{s}} & \text { fluid, solid densities } \\ \chi & \text { vertical shearing of fluid viscosity } \\ \frac{\partial}{\partial \mathrm{t}}, \frac{\partial}{\partial \mathrm{x}}, \frac{\partial}{\partial \mathrm{y}} & \text { partial differential operators }\end{array}$

Lituya Bay Megatsunami (Alaska) generated by an earthquake-induced landslide and the 1963 Vajont landslide (Italy) induced megatsunami (von Hardenberg 2011; Ward and Day 2011; Kafle 2019). Such events highlight the increasing interests for the fundamental, scientific and technological research in the relevant field in the Himalaya and also the need to design appropriate mitigation measures, hazard mappings and future planning (Masson et al. 2006).

Tsunamis are long water waves created by some sudden disturbances of the floor, surface or the banks of water body (Mohammed and Fritz 2012; Kafle 2014; Ma et al. 2015; Douglas 2016; Kafle et al. 2016; Kafle 2019; Kafle et al. 2019). Among the tsunamis caused by different geophysical triggering factors, landslide-generated tsunamis are more localized, thereby causing more local threats as compared to earthquake-generated tsunamis (Sammarco and Renzi 2008; Viroulet et al. 2013; Ma et al. 2015). Research in landslide generated tsunamis are very important for the safety of lives and infrastructures near the potential impact areas and construction of artificial reservoirs in mountains and valleys (Miao et al. 2014; Kafle 2019). The study of such events and the mitigation measures require physically-based models, efficient numerical tools and appropriate simulation techniques and strategic optimization of the defense measures (Pudasaini 2014; Kafle et al. 2016; Kattel et al. 2018; Mergili et al. 2018; Kafle et al. 2019).

Subaerial as well as submarine debris flows are generally gravity-driven multiphase (at least twophase) flows that constitute solid grains mixed with viscous fluid. The rheology and flow behaviour are largely controlled by the material composition. Researches in recent years are found to focus on different aspects of single- and two-phase landslides, debris avalanches and debris flows, and induced tsunami among which Pudasaini (2012) made an advancement by developing a general two-phase mass flow model down a channel that accounts for strong interactions between the constituent phases, incorporating buoyancy and other three dominant physical aspects of virtual mass force, generalized drag and enhanced non-Newtonian viscous stress induced by the changing sediment concentration in the debris mixture during the flow.

Pitman and Le (2005) developed a two-fluid model that includes simple drag force to describe unsteady and non-uniform flows as a mixture of the solid particles and the fluid. In the two-layered model of 


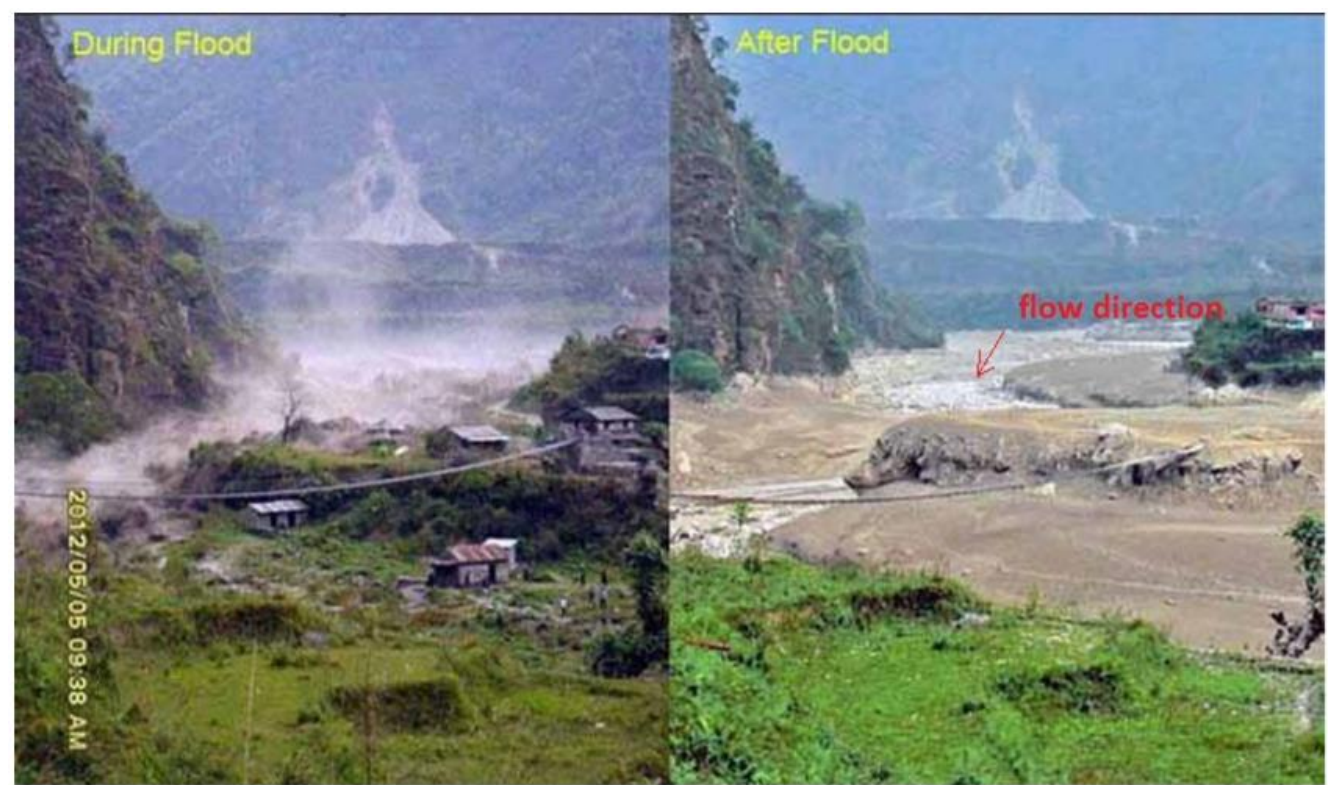

Fig. 1. View of the Seti River in Kharapani, Kaski District, Western Nepal, after the destruction by the debris and mud flow of May 5, 2012. Left: During the flood, some houses are seen on the bank of the river. Right: After the flood, the houses were swept away (Kattel 2014).

Jiang and LeBlond (1993), the deformable subaquaous landslide and associated tsunami waves were dynamically coupled. Ma et al. (2012) presented a shock-capturing three-dimensional nonhydrostatic dispersive surface wave model. Ma et al. (2015) presented a depth-averaged computational model for two-layer granular landslide and tsunami waves generation. Grilli et al. (2007) carried out numerical simulations to assess coastal tsunami hazards by performing tsunami simulations with the Boussinesq long wave model. Based on dimensional analysis and experimental data, Slingerl and Voight (1979) proposed an empirical logarithmic-equation for maximum wave amplitude as a function of landslide kinetic energy and water depth. Walder et al. (2003) demonstrated that the shape and height of the generated wave in near field depend on the water depth, the volume of the slide and the duration of the submerged landslide motion. Behroozi and Vaghefi (2020) considered the effects of fluid compressibility and energy depreciation in the reservoir boundaries by introducing a mesh free numerical model for the simulation of hydrodynamic response of damreservoir-foundation system. Kuswandi and Triatmadja (2019) elaborated the use of a dam break system to generate a surge model for the study of tsunami runup, run-down and scouring around a vertical cylinder.

The two-phase debris flows were simulated by Pudasaini (2012) for the first time for the explicit evolution of the solid and fluid phases as the subaerial debris mass collapses and slides down the slopes. Furthermore, Pudasaini (2014) simulated geometrically two-dimensional flows in which the two-phase subaerial debris flows impact the still reservoir downstream to produce tsunami at impact and the submarine debris mass slides along the bathymetric surface of the reservoir. For idealized geometry, Kafle (2014) further presented simulation results for two-phase and geometrically threedimensional subaerial flows impacting a fluid reservoir and observed some natural phenomena for the first time by using two-phase debris flow model (Pudasaini 2012). Kafle et al. (2016) further simulated two-phase and three-dimensional subaerial flows impacting a fluid reservoir, and the effects of the position of initial debris mass on the splash, tsunami generation and submarine debris mass movements along with impact and submergence times and scalings. The submerge time scaling for a deformable two-phase debris was found to deviate substantially from the same for a non-deformable solid. Mergili et al. (2018) studied the complex hydro-geomorphic process chains in a multi-lake outburst flood in the Santa Cruz Valley in Cordillera Blanca, Peru. Kafle and Tuladhar (2018) presented and discussed a simulation related to a partially submerged landslide impacting a quiescent reservoir. Through computational experiments, Kattel et al. (2018) analyzed different types of flow-obstacleinteractions including debris vacuum generation, flow obstruction, redirection and phase-separation. Kafle et al. (2019) presented geometrically threedimensional simulation results for a two-phase debris mass impacting a fluid reservoir containing obstacles of different sizes, dimensions and numbers, installed at different positions both in subaerial slopes and in bathymetric surface. Kafle and Kattel (2019) focused on the symmetric issues in the flow in different rotational symmetries and the obstacle shapes employing the general two-phase mass flow model (Pudasaini 2012) and the open source computational tool r.avaflow. Qiao et al. (2018) also used the same model to simulate and analyze the run out characteristics of the catastrophic landslide that occurred in 2015 at Hongao construction waste 
dumpsite in the Guangming New District of Shenzhen, China. The two-phase mass flow model (Pudasaini 2012) is also employed to construct a generalized quasi two-phase bulk mixture model Pokhrel et al. (2018), and an extended quasi-two phase mixture model (Khattri and Pudasaini 2018) capturing more physics of two-phase mass flows. The model equations are further modified in terms of stream function vorticity-formulation for mixture mass flow by Pokhrel and Pudasaini (2020).

In most of the existing works, numerical experiments were carried on by taking constant upstream slope (Pudasaini 2012; Kafle 2014; Pudasaini 2014; Kafle et al. 2016; Kattel et al. 2016; Kafle and Tuladhar 2018; Kattel et al. 2018; Qiao et al. 2018; Kafle 2019; Kafle et al. 2019). This may not be the case in many real field scenarios. Figure 2, as an example of sudden slope changes in the topography in the mountain flanks around the Everest Gokyo Lake. The slopes of the mountain flanks surrounding a glacial lake or the slopes of the side walls of artificially constructed reservoirs play important roles in the degree or intensity of splash on impact, amplitudes and propagation speeds of the resulting water waves and possible dam breaching or overspilling of water. Making the topography much closer to reality, here we present simulations for the cases with different sudden slope changes in the topography. The simultaneous dynamics of the twophase and geometrically three-dimensional subaerial and submarine landslide or debris flow, the resulting tsunami generation and propagation upon debris impact at a fluid reservoir or a lake, the subsequent submarine debris flow, turbidity current, particle transport, and the analyses of different types of waves and their complex interactions are presented in this work imposing different slope changes in different parts of the topography.

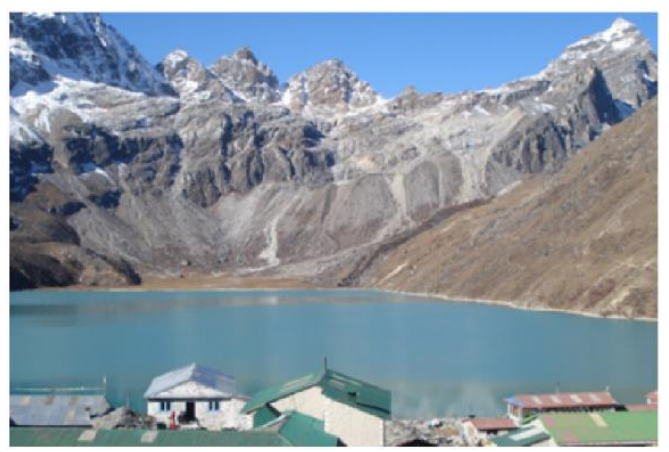

Fig. 2. The Everest Gokyo Lake: Slope changes can be seen in the mountain flanks followed by the lake (Source: trekkingtrail.com).

\section{PHYSICAL-MATHEMATICAL MODEL}

\subsection{Model Equations}

Now, we briefly mention the employed general twophase mass flow (Pudasaini2012). The two phases (sediments and viscous fluid) are described by their different material properties. The fluid phase is characterized by its material density $\rho_{f}$, viscosity $\eta_{f}$ and isotropic stress distribution. The solid phase is characterized by its material density $\rho_{s}$, internal friction angle $\phi$, the basal friction angle $\delta$, and an anisotropic stress distribution through the lateral earth pressure coefficient $K$. In the following model equations (1)-(6), $x, y$ and $z$ are coordinates along the downslope, cross-slope and the surface normal directions, respectively with $g^{x}, g^{y}$ and $g^{z}$ as the respective components of gravitational acceleration. The subscripts $s$ and $f$ stand for the solid and the fluid phases, and $\mathbf{u}_{f}=\left(u_{f}, v_{f}\right)$ and $\mathbf{u}_{s}$ $=\left(u_{s}, v_{s}\right)$ are the depth-averaged velocity components for fluid and for solid in the downslope $(x)$ and the cross-slope $(y)$ directions, respectively. The flow depth is $h ; \alpha_{s}$ is the solid-volume fraction in the mixture, so that $\alpha_{f}=1-\alpha_{s}$ is the fluid volume fraction. The depth-averaged nonlinear partial differential equations representing mass ((3)-(4)), and momentum ((5)-(6)) balances for solid and fluid in the downslope and the cross-slope directions are given by (Pudasaini 2012):

$$
\begin{aligned}
& \frac{\partial}{\partial \mathrm{t}}\left(\alpha_{\mathrm{s}} \mathrm{h}\right)+\frac{\partial}{\partial \mathrm{x}}\left(\alpha_{\mathrm{s}} \mathrm{hu} \mathrm{s}_{\mathrm{s}}\right)+\frac{\partial}{\partial \mathrm{y}}\left(\alpha_{\mathrm{s}} \mathrm{hv}_{\mathrm{s}}\right)=0 \\
& \frac{\partial}{\partial \mathrm{t}}\left(\alpha_{\mathrm{f}} \mathrm{h}\right)+\frac{\partial}{\partial \mathrm{x}}\left(\alpha_{\mathrm{f}} h \mathrm{u}_{\mathrm{f}}\right)+\frac{\partial}{\partial \mathrm{y}}\left(\alpha_{\mathrm{f}} \mathrm{hv}_{\mathrm{f}}\right)=0 \\
& \frac{\partial}{\partial t}\left[\alpha_{s} h\left(u_{s}-\gamma C\left(u_{f}-u_{s}\right)\right)\right] \\
& +\frac{\partial}{\partial x}\left[\alpha_{s} h\left(u_{s}^{2}-\gamma C\left(u_{f}^{2}-u_{s}^{2}\right)+\frac{1}{2} \beta_{x_{s}} h\right)\right]
\end{aligned}
$$$$
+\frac{\partial}{\partial y}\left[\alpha_{s} h\left(u_{s} v_{s}-\gamma C\left(u_{f} v_{f}-u_{s} v_{s}\right)\right)\right]=h S_{x_{s}},
$$

$\frac{\partial}{\partial t}\left[\alpha_{s} h\left(v_{s}-\gamma C\left(v_{f}-v_{s}\right)\right)\right]$

$$
\begin{aligned}
& +\frac{\partial}{\partial x}\left[\alpha_{s} h\left(u_{s} v_{s}-\gamma C\left(u_{f} v_{f}-u_{s} v_{s}\right)\right)\right] \\
& +\frac{\partial}{\partial y}\left[\alpha_{s} h\left(v_{s}^{2}-\gamma C\left(v_{f}^{2}-v_{s}^{2}\right)+\frac{1}{2} \beta_{y_{s}} h\right)\right]=h S_{y_{s}},
\end{aligned}
$$

$$
\frac{\partial}{\partial t}\left[\alpha_{f} h\left(u_{f}+\frac{\alpha_{s}}{\alpha_{f}} c\left(u_{f}-u_{s}\right)\right)\right]
$$$$
+\frac{\partial}{\partial x}\left[\alpha_{f} h\left(u_{f}^{2}+\frac{\alpha_{s}}{\alpha_{f}} C\left(u_{f}^{2}-u_{s}^{2}\right)+\frac{1}{2} \beta_{x_{f}} h\right)\right]
$$

$$
+\frac{\partial}{\partial y}\left[\alpha_{f} h\left(u_{f} v_{f}+\frac{\alpha_{s}}{\alpha_{f}} c\left(u_{f} v_{f}-u_{s} v_{s}\right)\right)\right]=h S_{x_{f}},(5)
$$




$$
\begin{aligned}
& \frac{\partial}{\partial t}\left[\alpha_{f} h\left(v_{f}+\frac{\alpha_{s}}{\alpha_{f}} C\left(v_{f}-v_{s}\right)\right)\right] \\
& +\frac{\partial}{\partial x}\left[\alpha_{f} h\left(u_{f} v_{f}+\frac{\alpha_{s}}{\alpha_{f}} C\left(u_{f} v_{f}-u_{s} v_{s}\right)\right)\right] \\
& +\frac{\partial}{\partial y}\left[\alpha_{f} h\left(v_{f}^{2}+\frac{\alpha_{s}}{\alpha_{f}} C\left(v_{f}^{2}-v_{s}^{2}\right)+\frac{1}{2} \beta_{y_{f}} h\right)\right]=h S_{y_{f}},(6)
\end{aligned}
$$

in which $\beta_{x_{s}}=\varepsilon K_{x} p_{b_{s}}, \beta_{y_{s}}=\varepsilon K_{y} p_{b_{s}}, \beta_{x_{f}}=$ $\beta_{y_{f}}=\varepsilon p_{b_{f}}, \quad p_{b_{f}}=-g^{z}, p_{b_{s}}=(1-\gamma) p_{b_{f}}$. Here, $p_{b_{f}}$ and $p_{b_{s}}$ are the effective fluid and solid pressures at the base. $\gamma$ is the ratio of fluid density to the solid density, $\mathrm{C}$ is the virtual mass coefficient (enhanced kinetic energy of the fluid phase induced by solid particles)

The source terms in the right hand sides of the Eqs. (3)-(6) are (Pudasaini 2012):

$$
\begin{aligned}
& S_{x_{s}}=\alpha_{s}\left[g^{x}-p_{b_{s}}\left(\frac{u_{s}}{\left|\mathbf{u}_{s}\right|} \tan \delta+\varepsilon \frac{\partial b}{\partial x}\right)\right]-\varepsilon \alpha_{s} \gamma p_{b_{f}} \\
& \cdot\left[\frac{\partial h}{\partial x}+\frac{\partial b}{\partial x}\right]+C_{D G}\left(u_{f}-u_{s}\right)\left|\mathbf{u}_{f}-\mathbf{u}_{s}\right|^{J-1}, \\
& S_{y_{s}}=\alpha_{s}\left[g^{y}-p_{b_{s}}\left(\frac{v_{s}}{\left|\mathbf{u}_{s}\right|} \tan \delta+\varepsilon \frac{\partial b}{\partial y}\right)\right]-\varepsilon \alpha_{s} \gamma p_{b_{f}} \\
& \cdot\left[\frac{\partial h}{\partial y}+\frac{\partial b}{\partial y}\right]+C_{D G}\left(v_{f}-v_{s}\right)\left|\mathbf{u}_{f}-\mathbf{u}_{s}\right|^{J-1}, \\
& S_{x_{f}}=\alpha_{f}\left[g^{x}-\varepsilon\left[\frac{1}{2} p_{b_{f}} \frac{h}{\alpha_{f}} \frac{\partial \alpha_{s}}{\partial x}+p_{b_{f}} \frac{\partial b}{\partial x}\right.\right. \\
& +\frac{1}{\alpha_{f} N_{R}}\left\{2 \frac{\partial^{2} u_{f}}{\partial x^{2}}+\frac{\partial^{2} v_{f}}{\partial y \partial x}+\frac{\partial^{2} u_{f}}{\partial y^{2}}-\frac{\chi u_{f}}{\varepsilon^{2} h^{2}}\right\} \\
& \left.+\frac{1}{\alpha_{f} N_{R_{\mathcal{A}}}}\left\{2 \frac{\partial \alpha_{s}}{\partial y}\left(u_{f}-u_{s}\right)+\frac{\partial \alpha_{s}}{\partial x}\left(v_{f}-v_{s}\right)\right)\right\} \\
& \left.+\frac{1}{\alpha_{f}}\left(u_{f}-u_{s}\right)\right) \\
& \left.+\frac{\partial}{\partial y}\left(\frac{\partial \alpha_{s}}{\partial x}\left(v_{f}-v_{s}\right)+\frac{\partial \alpha_{s}}{\partial y}\left(u_{f}-u_{s}\right)\right)\right\} \\
& -\frac{\xi \alpha_{s}\left(u_{f}-u_{s}\right)}{\varepsilon^{2} \alpha_{f} N_{R_{\mathcal{A}}} h^{2}}=\alpha_{f}\left[g^{y}-\varepsilon\left[\frac{1}{2} p_{b_{f}} \frac{h}{\alpha_{f}} \frac{\partial \alpha_{s}}{\partial y}+p_{b_{f}} \frac{\partial b}{\partial y}+\frac{\partial^{2} u_{f}}{\partial x \partial y}+\frac{\partial^{2} v_{f}}{\partial x^{2}}-\frac{\chi v_{f}}{\varepsilon^{2} h^{2}}\right\}\right. \\
& \left.\left.+u_{f}-u_{s}\right)\left|\mathbf{u}_{f}-\mathbf{u}_{s}\right|^{J-1}\left(v_{f}-v_{s}\right)\right)
\end{aligned}
$$


form, we directly apply the higher-order shockcapturing scheme, namely the Total Variation Diminishing Non-Oscillatory Central (TVD-NOC) difference scheme on it (Pudasaini and Hutter 2007; Pudasaini 2012).The discretization of the spatial and temporal domains are carried out with uniform stationary width $\Delta \mathrm{x}, \Delta \mathrm{y}$ and $\Delta \mathrm{t}$. The discrete mesh points will be denoted by $\left(\mathrm{x}_{\mathrm{i}}, \mathrm{y}_{\mathrm{j}}, \mathrm{t}^{\mathrm{n}}\right)$ and are defined as $\quad x_{i}=i \Delta x, i=0,1,2, \ldots ; y_{j}=j \Delta y, j=0,1,2, \ldots$; $\mathrm{t}^{\mathrm{n}}=\mathrm{n} \Delta \mathrm{t}, \mathrm{n}=0,1,2, \ldots$, where the mesh cell $\left(\mathrm{x}_{\mathrm{i}}, \mathrm{y}_{\mathrm{j}}\right)$ has the boundaries $\left(x_{i \pm \frac{1}{2}}, y_{j \pm \frac{1}{2}}\right)$, where $x_{i+\frac{1}{2}}=x_{i}+$ $\frac{\Delta x}{2}$, etc.

The staggered averages at $\left(\mathrm{x}_{\mathrm{i} \pm 1 / 2}, \mathrm{y}_{\mathrm{j} \pm 1 / 2}, \mathrm{t}^{\mathrm{n}+1}\right)$ are then computed by the cell averages at $\left(\mathrm{x}_{\mathrm{i}}, \mathrm{y}_{\mathrm{j}}, \mathrm{t}^{\mathrm{n}}\right)$.

Now,

$$
C_{i, j}=\left\{(x, y):\left|x-x_{i}\right| \leq \frac{\Delta x}{2},\left|y-y_{j}\right| \leq \frac{\Delta y}{2}\right\} .
$$

is the $(\mathrm{i}, \mathrm{j})^{\text {th }}$ cell covered region. For $(\mathrm{x}, \mathrm{y}) \in \mathrm{C}_{\mathrm{i}, \mathrm{j}}$, suppose $U_{i, j}^{n}$ denote the cell average over this region at time $\mathrm{t}^{\mathrm{n}}$. Then,

$$
\tilde{w}_{i, j}\left(x, y, t^{n}\right)=U_{i, j}^{n}+\sigma_{i, j}^{x}\left(x-x_{i}\right)+\sigma_{i, j}^{y}\left(y-y_{j}\right)
$$

is a piecewise linear reconstruction over the cell, where $\sigma_{i, j}^{\mathrm{x}}$ and $\sigma_{\mathrm{i}, \mathrm{j}}^{\mathrm{y}}$ respectively are the discrete slopes of $\mathrm{U}$ in the $\mathrm{x}-$ and $\mathrm{y}$-directions which are determined by a TVD-limiter (minmod limiter, in our case) (Pudasaini and Hutter 2007). The cell average $w_{i+1 / 2, j+1 / 2}^{n+1}$ at $\left(x_{i+1 / 2}, y_{j+1 / 2}, t^{n+1}\right)$ is given by (Pudasaini and Hutter 2007).

$$
\begin{gathered}
w_{i+1 / 2, j+1 / 2}^{n+1}=\frac{1}{4}\left\{w_{i, j}^{n}+w_{i+1, j}^{n}+w_{i+1, j+1}^{n}+w_{i, j+1}^{n}\right\} \\
+\frac{\Delta x}{16}\left\{w_{i, j}^{x}-w_{i+1, j}^{x}-w_{i+1, j+1}^{x}+w_{i, j+1}^{x}\right\} \\
+\frac{\Delta y}{16}\left\{w_{i, j}^{y}+w_{i+1, j}^{y}-w_{i+1, j+1}^{y}-w_{i, j+1}^{y}\right\} \\
-\frac{\Delta t}{2 \Delta x}\left\{f\left(w_{i+1, j}^{n+1 / 2}\right)+f\left(w_{i+1, j+1}^{n+1 / 2}\right)-f\left(w_{i, j}^{n+1 / 2}\right)\right. \\
\left.-f\left(w_{i, j+1}^{n+1 / 2}\right)\right\}-\frac{\Delta t}{2 \Delta y}\left\{g\left(w_{i, j+1}^{n+1 / 2}\right)+g\left(w_{i+1, j+1}^{n+1 / 2}\right)\right. \\
\left.-g\left(w_{i, j}^{n+1 / 2}\right)-g\left(w_{i+1, j}^{n+1 / 2}\right)\right\} \\
+\frac{\Delta t}{4}\left\{s\left(w_{i+1 / 4, j+1 / 4}^{n+1 / 2}\right)+s\left(w_{i+3 / 4, j+1 / 4}^{n+1 / 2}\right)\right. \\
\left.+s\left(w_{i+3 / 4, j+3 / 4}^{n+1 / 2}\right)+s\left(w_{i+1 / 4, j+3 / 4}^{n+1 / 2}\right)\right\} .
\end{gathered}
$$

CFL condition is maintained for stability, and an appropriate limiter (minmod) is used to avoid spurious oscillations in the solution domains
(Pudasaini and Hutter 2007).

\section{Simulating TWO-PHASE DEBRIS FLOW AND TSUNAMI}

Here, we simulate the two-phase landslide (or debris flow) and the resulting tsunamis, and their interactions when the upstream slope is kept constant in the first, then to make it closer to reality, with a sudden slope changes in the sliding planes and analyze and compare the results among sudden slope changes, and also with the constant upstream slope.

\subsection{Geometrical and Material Parameters}

For all of our simulations, we consider a (geometrically) three-dimensional and two-phase subaerial debris flow that hits a fluid reservoir downstream. The upper part of the channel is inclined downwards to the right and is flat $\left(\zeta=0^{\circ}\right)$ in the lateral direction (Fig. 3). Thus, the slope angles for the entire flow domain is given by

$$
\zeta=\left\{\begin{array}{lll}
\zeta_{1} & \text { for } & 0 \leq \mathrm{x} \leq 100 m, \\
\zeta_{2} & \text { for } & 100<\mathrm{x} \leq \mathrm{x}_{\mathrm{b}} m, \\
0 & \text { for } & \mathrm{x}_{\mathrm{b}}<\mathrm{x} \leq 300 m .
\end{array}\right.
$$

where $\mathrm{x}_{\mathrm{b}}=100 \times\left(1+1 / \tan \zeta_{2}\right)$ is the position of the bottom of the slope and $x_{\mathrm{lc}}=\mathrm{x}_{\mathrm{b}}-30 / \tan \zeta_{2}$ is left coast of the reservoir. Initially, the left end of the reservoir $\mathrm{x}=\mathrm{x}_{\mathrm{lc}}$ has the water height zero, which, due to the slope, gradually increases to its maximum of height of $30 \mathrm{~m}$ from the downslope coordinate $\mathrm{x}=\mathrm{x}_{\mathrm{lc}}$ to $\mathrm{x}=\mathrm{x}_{\mathrm{b}}$. Beyond this (from $\mathrm{x}=\mathrm{x}_{\mathrm{b}}$ to $x=300 \mathrm{~m}$ ), the initial fluid is at a constant height of $30 \mathrm{~m}$. As the debris moves downslope and hits the fluid reservoir, the generated tsunami will have the amplitude as the increased height of the water from its initial depth of $30 \mathrm{~m}$.

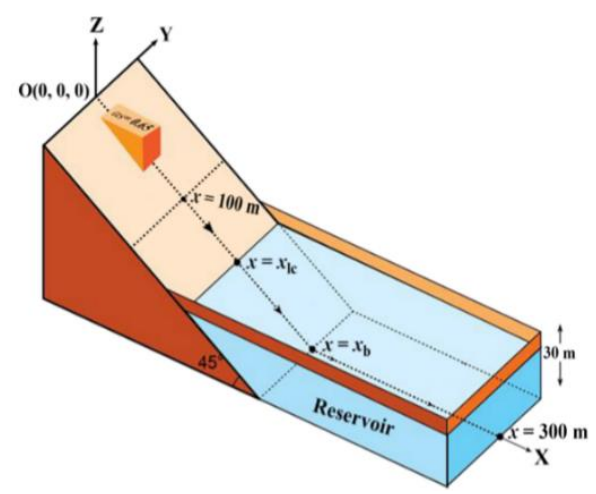

Fig. 3. A sketch of the initial configuration of a debris mass on an inclined slab and a fluid reservoir in the downstream. The figure has been modified from Kafle et al. (2016).

Initially at $\mathrm{t}=0 \mathrm{~s}$, the deformable debris mixture is in the form of a laterally-spanned triangular wedge $(20 \leq \mathrm{x} \leq 70 \mathrm{~m} ;-25 \leq \mathrm{y} \leq 25 \mathrm{~m})$ (Fig.3) which is uniformly distributed as a homogeneous mixture of 
$65 \%$ solid $\left(\alpha_{s}=0.65\right)$ and $35 \%$ fluid $\left(\alpha_{f}=0.35\right)$.

Similarly, the quiescent reservoir initially consists of $2 \%$ solid $\left(\alpha_{\mathrm{s}}=0.02\right)$ and $98 \%$ fluid $\left(\alpha_{\mathrm{f}}=0.98\right)$.

Thus, initially, the solid material height (in m) is given by

$$
\mathrm{h}_{\mathrm{s}}= \begin{cases}0.65(\mathrm{x}-20), & \text { for } 20 \leq \mathrm{x} \leq 70 \\ 0.02\left(30-\tan \zeta_{2}\left(\mathrm{x}_{\mathrm{b}}-\mathrm{x}\right)\right), & \text { for } \mathrm{x}_{\mathrm{lc}} \leq \mathrm{x} \leq \mathrm{x}_{\mathrm{b}}, \\ 0.02 \times 30, & \text { for } \mathrm{x}_{\mathrm{b}}<\mathrm{x} \leq 300, \\ 0, & \text { elsewhere. }\end{cases}
$$

Similarly, the fluid material height (in m) is given by

$$
\mathrm{h}_{\mathrm{f}}= \begin{cases}0.35(\mathrm{x}-20), & \text { for } 20 \leq \mathrm{x} \leq 70 \\ 0.98\left(30-\tan \zeta_{2}\left(\mathrm{x}_{\mathrm{b}}-\mathrm{x}\right)\right), & -25 \leq \mathrm{y} \leq 25 \\ 0.98 \times 30, & \text { for } \mathrm{x}_{\mathrm{lc}} \leq \mathrm{x} \leq \mathrm{x}_{\mathrm{b}} \\ 0, & \text { for } \mathrm{x}_{\mathrm{b}}<\mathrm{x} \leq 300\end{cases}
$$

The other common parameter values chosen for our simulations are $\phi=35^{\circ}, \delta=15^{\circ}, \rho_{\mathrm{f}}=1,100 \mathrm{kgm}^{-3}$, $\mathrm{N}_{\mathrm{R}_{\mathrm{A}}}=1,000, \mathrm{Re}_{\mathrm{p}}=1, \mathrm{U}_{\mathrm{T}}=5.0 \mathrm{~ms}^{-1}, \mathrm{P}=0.75$, $\mathrm{J}=1, \chi=3, \xi=5, \mathrm{C}=0.5$. Although this choice of parameters are based on the physics of the twophase subaerial and submarine mass flows (Pudasaini 2012; Pudasaini 2014; Kafle et al. 2016; Kattel et al. 2016; Mergili et al. 2017), the values can vary according to the properties of materials involved and flow situation.

\subsection{Simulation Results and Discussions}

Using the aforementioned initial geometrical settings and the material parameters, first we present a reference simulation with constant upstream slope of $45^{\circ}$ as described in Kafle et al. (2019). Then, a couple of simulation results are presented by increasing the slopes of the upper part of the upstream plane, and the other results by increasing the slopes of the lower part of the upstream plane. The results are compared with the reference simulations and also with each other.

\subsubsection{Constant upstream slope $\left(\tan 45^{\circ}\right)$}

Figure 4 presents a basic simulation for the total debris depth along with the reservoir with tsunami, and also the separate evolution of the solid phase, the penetration of the debris into the reservoir, and the debris-reservoir interaction similar to those presented in (Kafle et al. 2016) and (Kafle et al. 2019).

As soon as the debris flow is triggered, $(\mathrm{t}=0 \mathrm{~s}$, left panel a), the debris mass starts to shear both downslope and across. Due to this, the subaerial debris depth substantially decreases as shown by the colour bars given alongside of each panel. In Fig. 7Fig. 8, the arrows in the top panels represent the flow direction. At $t=1 \mathrm{~s}$, the maximum of the debris depth shifts quickly from the front to the main body. As the shearing continues, the debris depth becomes much lower than the reservoir height at $t=3 \mathrm{~s}$. The flowing mass already hits the centre of the left coast of the reservoir $\left(\mathrm{x}_{\mathrm{lc}}=170 \mathrm{~m}\right)$ to generate a tsunami at about $\mathrm{t}=5 \mathrm{~s}$ (left panel $\mathrm{d}$ ) that propagates immediately downslope and across. Since the debris mass further hits the reservoir with higher momentum, the tsunami is expanded in the vicinity of the impact $(t=7 \mathrm{~s}$, left panel $\mathrm{e})$. As more fluid mass from the left of the reservoir is strongly pushed forward and laterally during the flow, it produces a strong hydrodynamic impact vacuum (Pudasaini 2014), or crater (Fritz et al. 2003) at $\mathrm{t}=9 \mathrm{~s}$. For $5 \leq \mathrm{t} \leq 9 \mathrm{~s}$, amplified three-dimensional tsunami waves are observed along with the three complex phenomena (Kafle et al. 2016): (i) a subaerial debris flow in the upstream region, (ii) submarine debris flow in the reservoir, and (iii) a tsunami (on the order of $10 \mathrm{~m}$ ) on the surface of the reservoir. The colour map indicates that the tsunami has propagated in all directions. The debris mass totally enters the reservoir nearly at $t=9 \mathrm{~s}$. The effect of the impact still persists even in $t=9 \mathrm{~s}$, showing impact vacuum during the splash.

As the fluid-only and the total geometric evolutions are qualitatively similar due to the dominant fluid volume in the reservoir, we do not show the fluid behaviour separately. However, the dynamics of the solid phase (Fig. 4B) is drastically different, mainly in the reservoir as a submarine mass movement. As the initial debris mass collapses, the front rarefies and accelerates downstream mainly due to the pressure gradient and gravity, whereas the rear part takes some more time to spread and to slide downslope due to the friction and the hindrance of the rear part by the flow front. However, from $t=1 \mathrm{~s}$ (right panel $b$ ) to $t=3 \mathrm{~s}$ (right panel $\mathrm{c}$ ), the position of the relative maximum depth has shifted a bit upslope. At $\mathrm{t}=5 \mathrm{~s}$ (right panel d), the maximum depth position is shifted downslope as the initial solid mass in the rear part has moved downslope. In Fig. 4B, maximum solid depth has continuously decreased from $30 \mathrm{~m}$ at $\mathrm{t}=0 \mathrm{~s}$ to around $3.5 \mathrm{~m}$ at $\mathrm{t}=5 \mathrm{~s}$ by its spreading, and increased to a bit more than $7 \mathrm{~m}$ at $\mathrm{t}=$ $7 \mathrm{~s}$ because of the beginning of the solid deposition process. The deposition process continues to $t=9 \mathrm{~s}$ as shown by the further increase of the solid depth to nearly $11 \mathrm{~m}$. As the elongated solid tail that appeared in the previous time slices has already shortened and accumulated almost in the solid head, we stop the simulation at $\mathrm{t}=9 \mathrm{~s}$. Due to the impact of the subaerial debris on the reservoir, the solid mass has also been sheared and elongated cross-wise from the front to the middle portion $(t=5 \mathrm{~s}$, right panel $\mathrm{d})$, where the impact has influenced the dynamics. The lateral boundaries of the reservoir have no significant effect on the lateral shearing. Due to the impact, the lateral spreading of the solid mass has increased from $\mathrm{t}=5 \mathrm{~s}$ (right panel d) to $\mathrm{t}=9 \mathrm{~s}$ (right panel $\mathrm{f}$ ). At $\mathrm{t}=$ $8 \mathrm{~s}$, the solid debris part has just crossed the coastal line $(\mathrm{x}=170 \mathrm{~m})$, which is not shown here. We also observe that the sliding mass changes its geometrical shape by its deformation mainly after it hits the fluid 

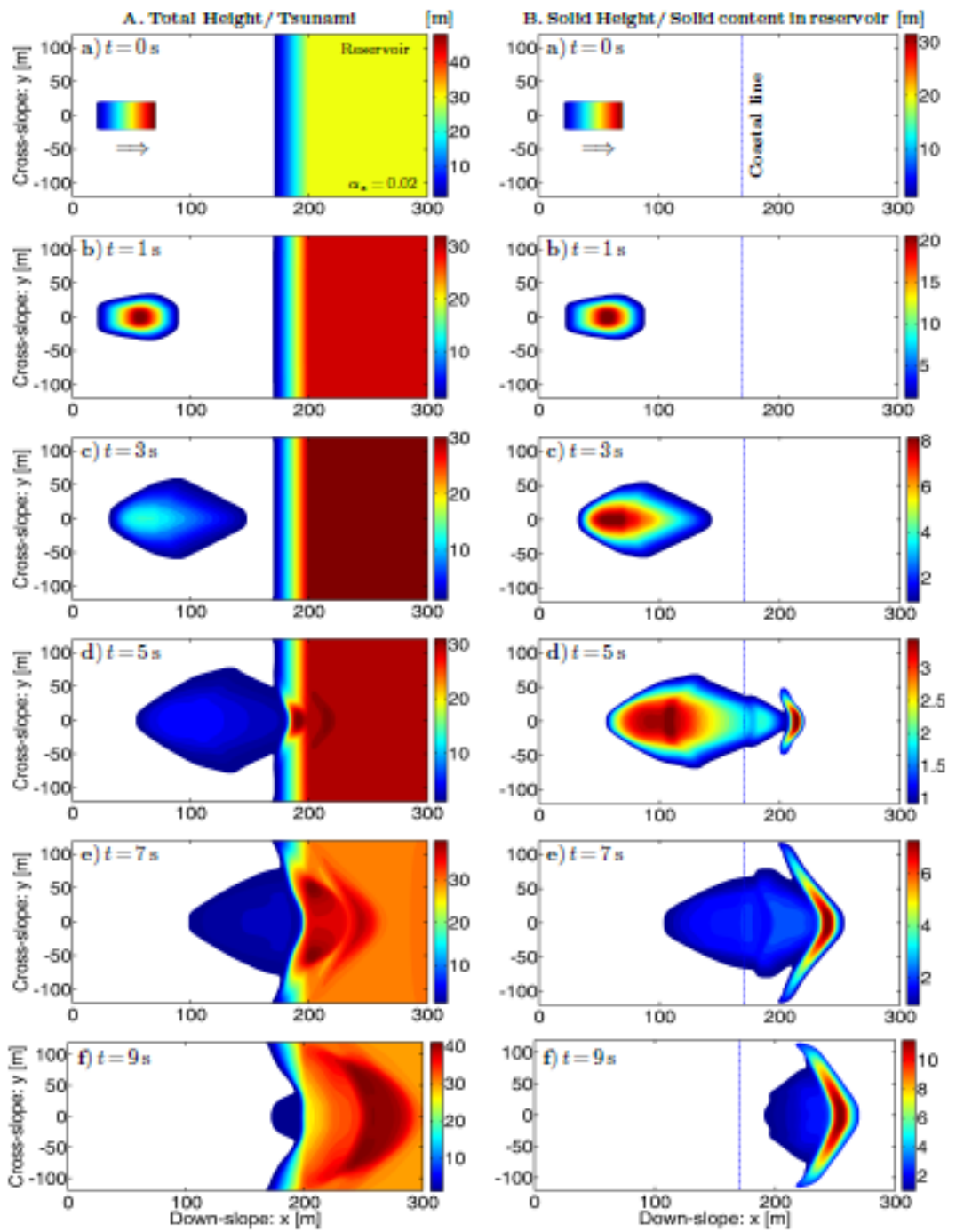

Fig. 4. Constant topographic slope. A: Total height of the debris mass and tsunami waves. As time elapses, the formation, amplification and propagation of three-dimensional tsunamis are observed as subaerial two-phase debris mass impacts the quiescent water reservoir. B: Evolution of the solid phase alone in the debris mixture. As soon as mass is released, the front rarefies and accelerates. After $t=5 \mathrm{~s}$,

the solid mass forms a very special forward propagating laterally wide and curved wave of solid component (solid-wave). The vertical line in blue at $x=x_{l c}(=170 \mathrm{~m})$ indicates the left coast of the reservoir (Kafle et al. 2019).

reservoir at $\mathrm{t}=5 \mathrm{~s}$. The impact of the solid mass on the fluid reservoir, from $t=5 \mathrm{~s}$ to $\mathrm{t}=9 \mathrm{~s}$ (right panel) leads to the formation of a very special for ward propagating laterally wide and curved solid-wave.

Using this as the reference simulation, next we perform some other simulations by varying the slopes in different parts of the upstream sliding plane. First we vary the slopes of the upper part, and in the other set of computational experiments, we vary the slopes of the lower part.

\subsubsection{Variation of the Slopes of the Upper Part of the Upstream Plane}

Due to some previously occurred landslides and the upstream moving shock during deposition, the topography might change such that the upper part of the flow path gets steeper than its lower part. To capture this potential realistic scenario, we perform a couple of computational experiments keeping all the material and geometric parameters the same as those in Fig. 4, except we increase the slope of the upper part of the upstream plane.

A. Sudden slope change to $\tan 60^{\circ}$ : Figure 5 presents the simulation result when the plane is inclined at $60^{\circ}$ for $\mathrm{x} \leq 100 \mathrm{~m}$ and suddenly the inclination is changed back to $45^{\circ}$ for $100 \mathrm{~m}$ $<\mathrm{x} \leq \mathrm{x}_{\mathrm{b}}(=200 \mathrm{~m}$, up to the bottom of the reservoir). The slope of the upper part of the upstream plane is higher as compared to Fig. 4. As the gravity force is 

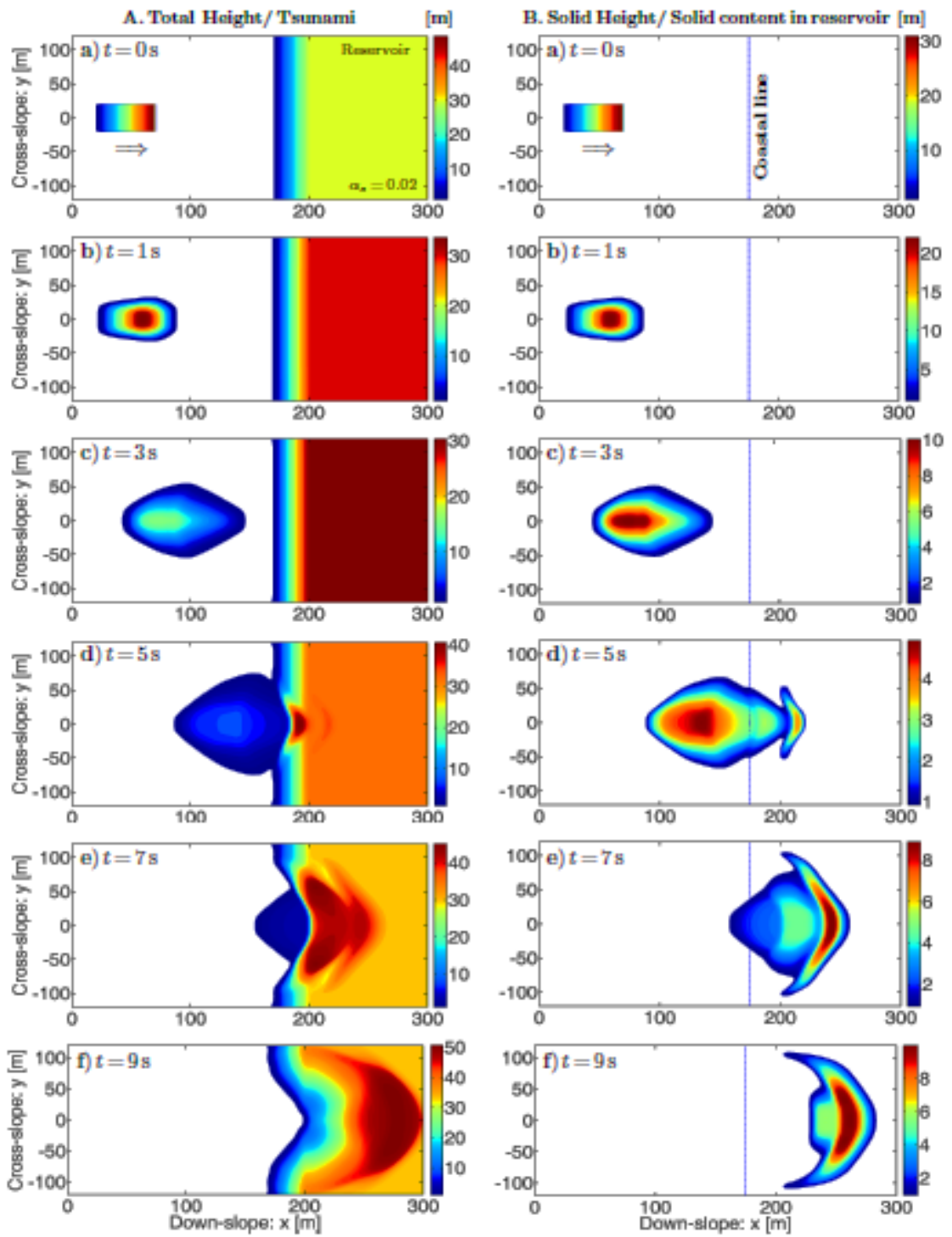

Fig. 5. Sudden slope change of the upper part of the upstream plane from $\tan 45^{\circ}$ to $\tan 60^{\circ}$. A: Total height of the debris mass and tsunami waves when the topography is inclined at $60^{\circ}$ for $0 \leq x \leq$ $100 \mathrm{~m}$ and suddenly the inclination is changed back to $45^{\circ}$ for $100 \mathrm{~m}<x \leq \boldsymbol{x}_{\boldsymbol{b}}=\mathbf{2 0 0 \mathrm { m }}$. B: Evolution of the solid phase alone in the debris mixture. Due to the increased slope, the produced tsunami is more intensified and travels longer distance downstream. The vertical line in blue at $x=x_{l c}(=170 \mathrm{~m})$ indicates the left coast of the reservoir.

increased, velocity of the debris mass is increased. Because of this, the debris mass hits the left coast of the reservoir already at $t=4 \mathrm{~s}$ in Fig. $5 \mathrm{~A}$, but it occurred only at $\mathrm{t}=5 \mathrm{~s}$ in Fig. 5A. Amplitudes of the tsunami waves are of $10 \mathrm{~m}, 25 \mathrm{~m}$ and $20 \mathrm{~m}$ in Fig. $5 \mathrm{~A}$ whereas they were of just $1 \mathrm{~m}, 8 \mathrm{~m}$ and $10 \mathrm{~m}$ (approximately) in Fig. 4A at $\mathrm{t}=5 \mathrm{~s}, 7 \mathrm{~s}$ and $9 \mathrm{~s}$, respectively. This is because the debris mass with higher momentum produces higher degree of splash on impact with the reservoir so as to produce tsunami waves with higher intensity.

On analyzing the dynamics of the submarine mass (solid mass inside the reservoir) in Fig. 5B, we notice that the solid mass also moves faster as compared to that in Fig. 4B. At $\mathrm{t}=7 \mathrm{~s}$, solid mass is almost submerged in Fig. 5B whereas a considerable portion of the solid mass is still in the subaerial slope in Fig. 4B. So, we observe that submerged time is decreased when we increase the slope or the inclination of the upper part of the sliding plane. The results demonstrate the strong impact of the sudden slope change of the upstream sliding plane, especially in the formation and propagation of very special and dynamically different solid- and fluid-structures in the reservoir.

B. Sudden steeper slope change to $\tan 75^{\circ}$ : When the upper upstream inclination is increased to steeper value $\left(75^{\circ}\right)$ than the previous cases, but keeping the 

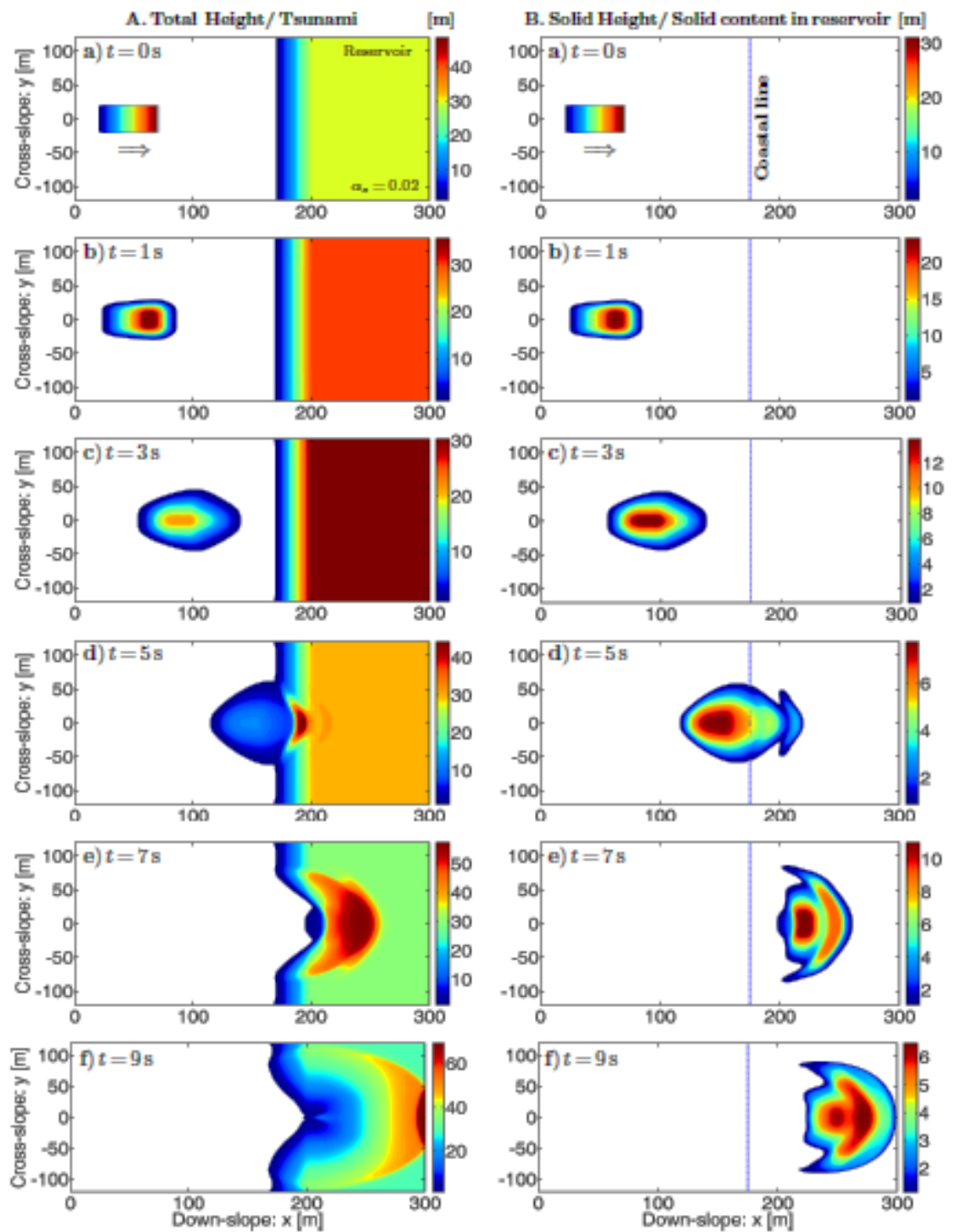

Fig. 6. Sudden steep slope change of the upper part of the upstream plane. A: Total height of the debris mass and tsunami waves when the sliding plane is inclined at $75^{\circ}$ for $0 \mathrm{~m} \leq x \leq 100 \mathrm{~m}$, and suddenly the inclination is changed back to $75^{\circ}$ for $100 m<x \leq x_{b}=200 \mathrm{~m}$. B: Evolution of the solid phase alone in the debris mixture. Tsunami intensity and downstream propagation further increase.

The vertical line at $x=x_{l c}(=170 \mathrm{~m})$ indicates the left coast of the reservoir.

inclination of the lower part constant (i.e., $75^{\circ}$ ), the landslide or debris mass accelerates more rapidly due to the more increased gravity force in the upper part (Fig. 6). This produces even higher impact on the reservoir producing more largely intensified tsunami (of amplitudes $22 \mathrm{~m}, 25 \mathrm{~m}, 38 \mathrm{~m}$ at $\mathrm{t}=5,7$ and $9 \mathrm{~s}$ respectively) as compared to the previous cases. It is because the larger amount of the transported debris mass with higher mobility transfers higher energy to the fluid in the reservoir on impact. The tsunami propagates more downslope than cross-slope and has already crossed the right coast of the reservoir at $t=$ $9 \mathrm{~s}$. As the mechanically stronger solid-rich submarine mass hits the right coast of the reservoir at $t=9 \mathrm{~s}$, there is possibility of breaching the right coastal dam, threatening downstream population. To mitigate such potential hazard, installing submarine obstacles can be useful by decreasing the tsunami propagation, thereby decreasing the submarine mass impact on the right coast of the reservoir. For details, one can refer to Kafle et al. (2019).

At $\mathrm{t}=7 \mathrm{~s}$, the solid mass already gets totally submerged in the reservoir in Fig. 6B whereas some parts of the flowing debris mass were still in the subaerial slope at this time slice in the two previous cases (Fig. 5B and Fig. 4B). Debris mass is more mobile with decreased submerged time when we increase the slope of the upstream part. At $t=7 \mathrm{~s}$, a cross wise elongated local maxima is followed by the other maximum which is more localized. The solid phase also advects more downslope in Fig. 6B than in Fig. 5B and Fig. 4B. The front position of the solid mass are at the downslope distances of $\mathrm{x}=260 \mathrm{~m}, \mathrm{x}$ $=280 \mathrm{~m}, \mathrm{x}=300 \mathrm{~m}$ in Fig. 4 , Fig. 5 and Fig. $6 \mathrm{~B}$ 
respectively at $t=9 \mathrm{~s}$. This leads to completely different dynamics and depositional behaviour of the submarine landslide for a more steeply changing upstream slopes as compared to those with lower slopes. This implies that it might be dangerous to make civil structures around the banks of the water bodies surrounded by mountain flanks with steep upstream slopes.

Next, we vary the slope of the lower part of the sliding plane, analyze the results and compare them with the constant slope and the variation of the slopes of upstream plane.

\subsubsection{Slope Variation in the Lower Part of the Upstream Plane}

In a natural topography, we sometimes observe that the inclination of the lower part of upstream plane is greater than the upper part due to some construction of civil structures or due to erosion in the bottom part of the flanks due to the water waves. To model this situation, we present a pair of computational experiments when the lower part of the upstream slopes $\left(100 m<x \leq x_{b}\right)$ are increased to $\tan 60^{\circ}$ and $\tan 75^{\circ}$.

A. Sudden slope change to $\tan 60^{\circ}$ : Figure 7 describes the evolution of the debris bulk, the resulting tsunami and the solid portion of the debris mass when the lower part of the upstream plane is increased to $\tan 60^{\circ}\left(100 \mathrm{~m}<\mathrm{x} \leq \mathrm{x}_{\mathrm{b}}=157.73 \mathrm{~m}\right)$. In this case, the debris mass is more accelerated as it flows downslope in the lower part of the upstream plane. However, this geometrical orientation shifts the left coast of the reservoir to some distance upstream $\left(x_{l c}=140.41 \mathrm{~m}\right)$ as compared to the previous cases. Because of this, it is interesting to observe that the debris mass already hits the left coast of the reservoir at $\mathrm{t}=3 \mathrm{~s}$, whereas in Fig. 4, the debris mass was yet much further upstream from the left coast of the reservoir. At $t=5 \mathrm{~s}$, larger impact force of flowing debris mass produces higher intensity tsunami $(10 \mathrm{~m})$ in Fig. 7 as compared to the case of the constant slope of the upstream plane (Fig. 4). As a kink is formed due to the sudden slope change in the lower part of upstream slope, the intensity of tsunami is amplified. In Fig. 7 at $t=9$ s, the debris mass is yet to reach the right coast of reservoir ( $\mathrm{x}=$ $290 \mathrm{~m}$ ), but in the previous cases it had already hit the right coast of the reservoir. This change in the geometry makes the reservoir longer so that the debris travels along the submarine environment earlier than the previous cases. This change in dynamical interaction of the debris with the reservoir dissipates more energy. This results in the shortening of the run out distance.

In Fig. 7B, we observe that the submarine mass is less mobile along the reservoir basin due to the drastic change of inclination from $60^{\circ}$ to $0^{\circ}$ during the transition of the topography from the inclined plane to the horizontal bottom $\left(\mathrm{x}_{\mathrm{b}}=157.73 \mathrm{~m}\right)$. At $\mathrm{t}$ $=9 \mathrm{~s}$, two weakly separated local maxima are observed in the cross-slope direction. The solid part of the debris mass is more elongated across in Fig.7B as compared to the previous figures (Fig. 4B - Fig. $6 \mathrm{~B})$. This geometrical change in the slope topography can be an effective measure to decrease the tsunami and the submarine mass impact downslope.

B. Sudden rapid slope change to $\tan 75^{\circ}$ : When the lower upstream plane $\left(100 \mathrm{~m}<\mathrm{x} \leq \mathrm{x}_{\mathrm{b}}=126.79 \mathrm{~m}\right)$

is increased to $75^{\circ}$ by keeping the upper part of the upstream plane $(0 \mathrm{~m} \leq \mathrm{x} \leq 100 \mathrm{~m})$ constant, the landslide mass although accelerates more in Fig. 8 than in Fig. 4 and Fig. 7, the tsunami and the submarine mass runouts both decrease in length. The major portion of the sliding debris mass already hits the left coast of the reservoir $\left(x_{l c}=\right.$ $118.75 \mathrm{~m}$ ) earlier (at $\mathrm{t}=3 \mathrm{~s}$ ) in comparison to all the previous cases, where the sliding debris mass was yet to strike or had just started to meet the left coast of the reservoir. In this case, the tsunami of high amplitude $(10 \mathrm{~m})$ is created even at $\mathrm{t}=3 \mathrm{~s}$ that later propagates less downslope but more cross slope. The early warning system can be more effective in this slope change.

The front of the flowing debris mass is at $275 \mathrm{~m}$ at $\mathrm{t}$ $=9 \mathrm{~s}$ in Fig. 8A, whereas it was at $290 \mathrm{~m}$ in Fig. 7A and had just reached the right coast of reservoir in the Fig. 4A. Here, we observe that when we increase the slope of the lower part of the upstream plane, the runout distance of the debris mass is substantially decreased. In this geometrical setting of the slope and reservoir, energy dissipates more, and so there is less risk of dam breaching at the right coast than in other cases. As the tsunami and submarine mass are farther upstream in this case, there is less threat to the downstream population and infrastructure as compared to the previous cases. In Fig. 8B, two cross wise elongated frontal local maxima are followed by one strong and centralized local maximum at $\mathrm{t}=5 \mathrm{~s}$.

Unlike in the previous cases, the solid phase reveals three localized maxima, two at the front and one at a bit back at $7 \mathrm{~s}$ and $\mathrm{t}=9 \mathrm{~s}$. The cross-slope elongations of the solid front occurred mainly at $\mathrm{t}=7 \mathrm{~s}$ and $\mathrm{t}=9 \mathrm{~s}$. The major portion of the solid mass is accumulated near to the bottom of the slope $(t=5$ to $t=9 \mathrm{~s})$. Such results may be extended and applied to hazard mitigation and to design less hazard-prone reservoirs for recreation and hydroelectric power generation.

Our results show that the variations in the slopes of the upper and the lower upstream parts of the topography give rise to different flow dynamics of the landslide, impacts on the reservoir, production and propagation of differently intensified tsunami, and different deposition morphology of the submarine mass. These results may help for the proper modeling of landslide and debris induced mountain tsunamis or water waves in rapidly changing slopes, the dynamics of turbidity currents and highly concentrated sediment transports in fluid reservoirs in high mountain slopes, channels, and reservoirs. 

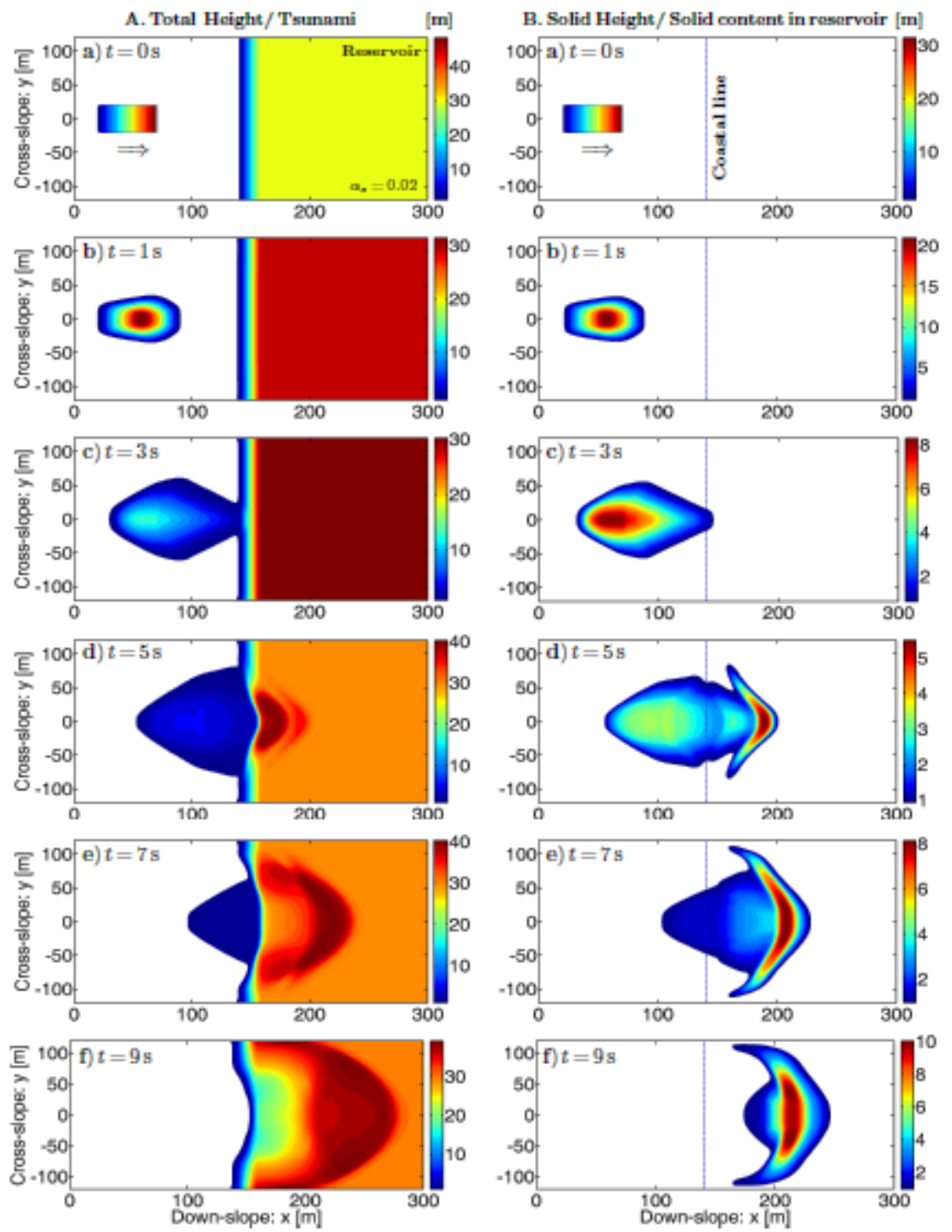

Fig. 7. Sudden slope change of the lower part of the upstream slope. A: Total height of the debris mass and tsunami waves when the topography is inclined at $45^{\circ}$ for $x \leq 100 \mathrm{~m}$, and suddenly the inclination is increased to $60^{\circ}$ for $100 m<x \leq x_{b}=157.73 \mathrm{~m}$. Due to the larger gravity force, the debris mass hits the left coast of the reservoir with higher impact force, and so the tsunami is more intensified than in

Fig. 4. B: Evolution of the solid phase alone in the debris mixture. The vertical line in blue at $x=$ $x_{l c}(=140.41 \mathrm{~m})$ indicates the left coast of the reservoir.

\subsection{Comparisons of Tsunami Amplitudes and Solid Front Positions}

Now, we compare the time evolutions of the tsunami amplitudes and the front positions of the solid phase in the different simulations presented in Fig. 4 - Fig. 8. We have taken into accounts of the outputs of other times also in the plots of Fig. 9. In Fig. 9 (Left), we compare the amplitudes of the fluid waves. In the reference simulation with constant upstream slope with inclination $45^{\circ}$ (Fig. 4), the highest tsunami amplitudes are of approximately $9 \mathrm{~m}$ (at around $\mathrm{x}=$ $200 \mathrm{~m}$ ) and $10 \mathrm{~m}$ (at around $\mathrm{x}=250 \mathrm{~m}$ ) at time $\mathrm{t}=7 \mathrm{~s}$ and $t=9$ s respectively. When the upper part of the upstream plane in different simulations are made steeper by keeping the lower part with constant slope (Fig. 5 and Fig. 6), the waves begin to generate almost from the same time but with higher amplitudes. On comparing Fig. 4 -Fig. 6 we observe that the tsunami amplitudes increase along with the slopes of the upper part of the upstream plane as time progresses. The increase of the inclination of $15^{\circ}$ has doubled the maximum amplitudes at $t=9 \mathrm{~s}$. On contrary, the maximum amplitudes are observed to be nearly the same when the lower parts of upstream plane are made steeper keeping the slope of the upper part constant. Since the flow impacts the lake less farther downslope, the waves begin to generate and acquire the maximum amplitudes at early times (nearly at $\mathrm{t}=3 \mathrm{~s}$ in Fig. 7and at $\mathrm{t}=5 \mathrm{~s}$ in Fig. 8). 

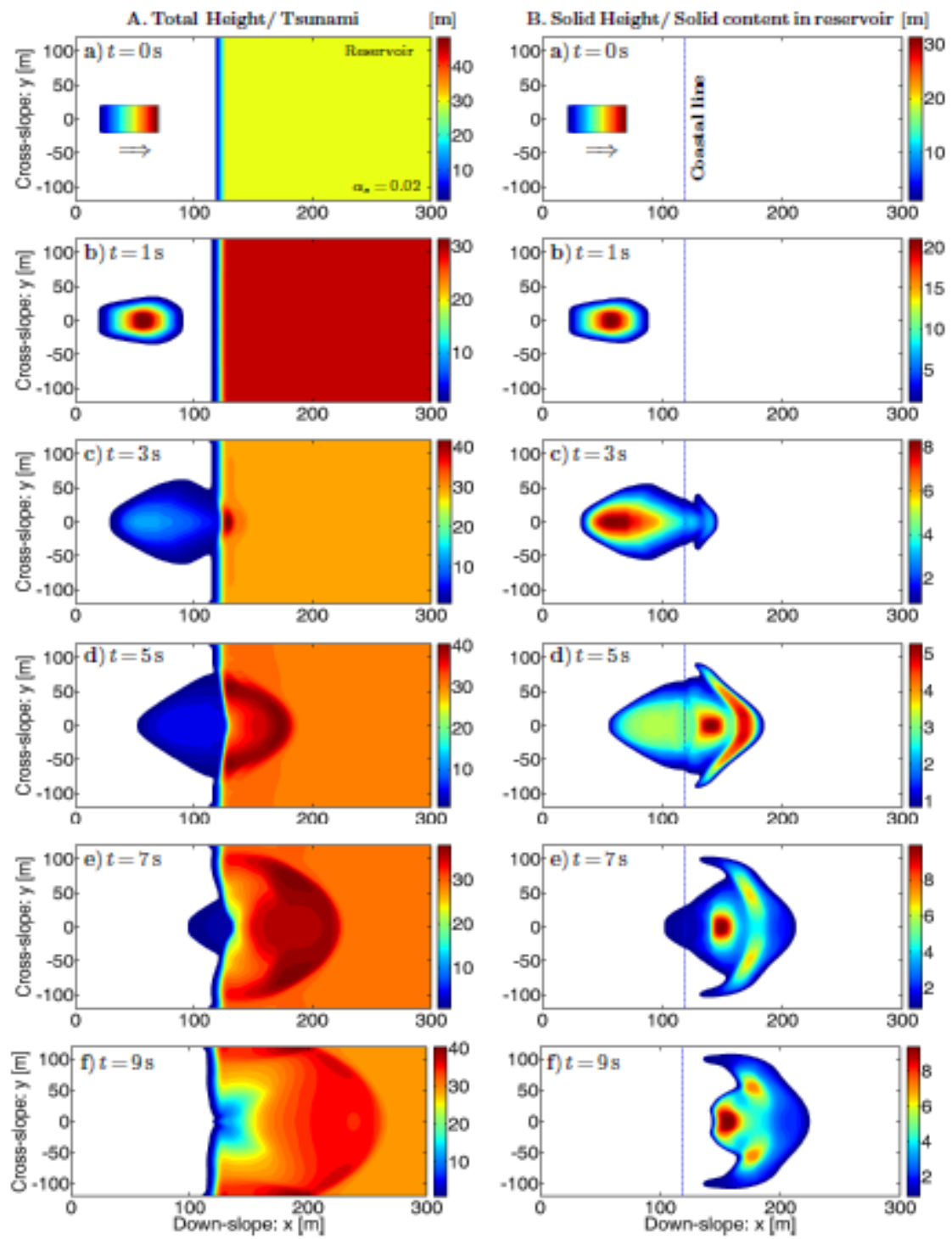

Fig. 8. Sudden steeper slope change of the lower part of the upstream plane. A: Total height of the debris mass and tsunami when the sliding plane is inclined at $45^{\circ}$ for $0 \mathrm{~m} \leq x \leq 100 \mathrm{~m}$ and suddenly the inclination is changed to $45^{\circ}$ for $100 m<x \leq x_{b}=126.79 m$. Due to even higher impact of the reservoir by debris mass, the magnitude of the tsunami is more intensified than the previous cases. B: Evolution of the solid phase alone in the debris mixture. At $t=7 \mathrm{~s}$, a relative maximum is at the back and two separated relative maxima are at the front of the solid-part. The vertical line in blue at $x=$ $x_{l c}(=118.75 m)$ indicates the left coast of the reservoir.

Later, the amplitudes begin to decrease slightly as time progresses. However, in case of Fig. 8, the amplitude slightly increases after $\mathrm{t}=7 \mathrm{~s}$ as the waves begin to localize at the lateral boundaries. In Fig. 6A, when the inclination of the upper part of the upstream plane is increased to $75^{\circ}$, the amplitude increases rapidly by nearly $(((40-10) / 10) \times 100 \%=) 300 \%$ whereas in Fig. 8A when the lower part of the upstream slope is increased to $75^{\circ}$, the tsunami amplitude is nearly same to the reference simulation with constant upstream slope (Fig. 4). Fig. 9 (Right) presents the comparison of solid front positions downslope for the different configurations (Fig. 5Fig. 8) among themselves and also with the reference simulation Fig. 4A (constant upstream slope) from $t$ $=0 \mathrm{~s}$ to $\mathrm{t}=9 \mathrm{~s}$. Initially, for all the simulations, the front position is at $\mathrm{x}=75 \mathrm{~m}$. As the flow is triggered, it moves downslope. In due course of the flow, due to different slopes of the sliding plane, the solid maxima evolve differently and lie at different downslope and cross-slope positions at the sliding plane and the reservoir. On comparing the solid front positions, they move downslope along with the time elapses. As the slope increases in the upper part of the upstream plane, the solid front accelerates more due to the increased gravity and so it reaches farther downslope (nearly at $280 \mathrm{~m}$ in Fig. 5 and at $300 \mathrm{~m}$ in Fig.6) at $\mathrm{t}=9 \mathrm{~s}$. Instead if the slope of the lower upstream plane is increased (Fig.7 and Fig. 8 the flow 

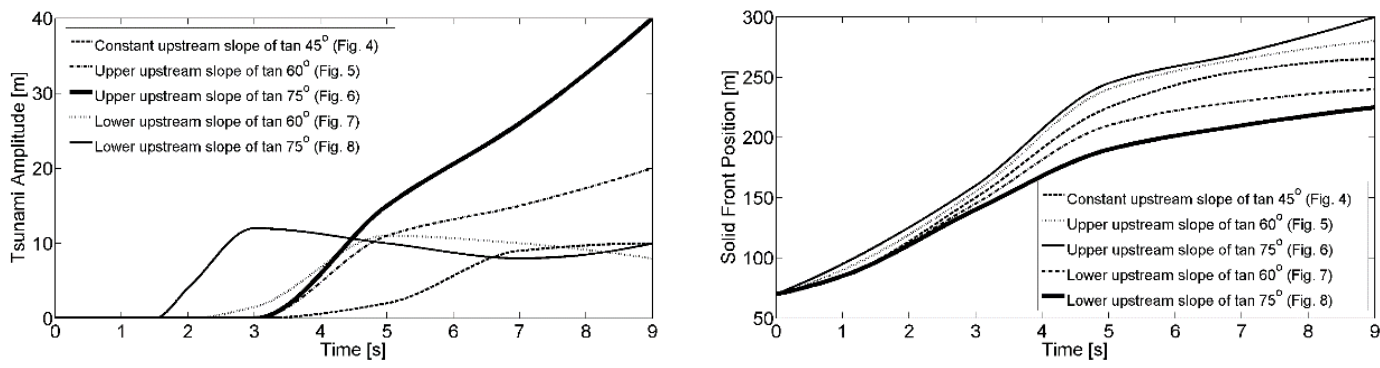

Fig. 9. Left: Comparison of tsunami amplitudes Right: Comparison of solid front positions for different slope variations at $\mathrm{t}=0$ and $\mathrm{t}=9 \mathrm{~s}$.

gets less space to increase its momentum in the subaerial slope and it impacts the reservoir earlier. Because of this, the solid front travels less farther downslope. On comparing the solid front positions with that in the reference simulation (Fig.4), it advects further in Fig. 6 by $((300-265) / 265) \times 100 \% \approx 13.2 \%$ and it lags in Fig. 8 by $((265-225) / 265) \times 100 \% \approx 15.1 \%$. The simulation results show that tsunami amplitudes and runout extents are rapidly increased when the upper part of the upstream plane is increased (See, Fig.9). In this case, there is danger of the possible dam break downstream, threatening downstream coastal population and infrastructures. Moreover, runout extent is rapidly decreased when the lower part of the upstream slope is increased (See, Fig.9). In this case, the mobility of both tsunami and submarine mass are substantially decreased by reducing the destructive wave impact, runup and the resulting damages. However, the threats in lateral directions increase since water waves are redirected more across than downslope. These simulation results clearly demand stronger right coastal walls in case of steeper upper part of the topography, and stronger lateral walls in case of the steeper lower part of the topography. Thus, the study of the effects of variation of the slopes of the topography in different parts can be useful for the mitigation of the hazard posed by tsunami and submarine mass movements for the coastal and mountain population and infrastructures.

\section{CONCLUSION}

The general two-phase debris flow model together with unified high resolution computational tool have been implemented to study the landslide and induced tsunami for the constant and varying slopes of the topography. The results demonstrate strong influence of the sudden slope changes of the topography in the formation and propagation of tsunami and the dynamics of submarine mass when landslide or debris flow impacts still water body. This leads to completely different dynamics and depositional behaviour of the submarine landslide for more steeply changing upstream slopes as compared to those with lower slopes. Through numerical experiments, we suggested that it might be dangerous to make civil structures around the banks of the water bodies surrounded by mountain flanks with steep upstream slopes. When we increase the slope of the lower part of the upstream plane, the runout distance of the debris mass is substantially decreased. It is due to the large energy dissipation of the debris mass inside the water reservoir. This geometrical arrangement of the slope and the reservoir is useful to prevent the submarine debris mass to breach the right coast of the reservoir. The results also show that the variation of the slopes of the upper and the lower upstream parts of the topography cause different flow dynamics of the landslide, impacts on the reservoir, produce different tsunami intensity and propagation, and possess different deposition morphology of the submarine landslide. The results can be used for the proper modeling of landslide and debris induced mountain tsunamis in rapidly changing slopes, to study the dynamics of turbidity currents and sediment transports in fluid reservoirs located in mountain slopes.

\section{ACKNOWLEDGEMENT}

Jeevan Kafle acknowledges University Grants Commission (UGC), Nepal, for the financial support provided as a Small Research Development and Innovation Grant (SRDIG) [SRDIG. 76/77- S\&T.1]

\section{REFERENCES}

Behroozi, A. M. and M. Vaghefi (2020). Radial basis function differential quadrature for hydrodynamic pressure on dams with arbitrary reservoir and face shapes affected by earthquake. Journal of Applied Fluid Mechanics 13(6), $1759-1768$.

Douglas, S. (2016). Numerical Modeling of Extreme Hydrodynamic Loading and Pneumatic Long Wave Generation: Application of a Multiphase Fluid Model. Ph. D. thesis, University of Ottawa, Canada.

Fritz, H. M., W. H. Hager and H. E. Minor (2003). Landslide generated impulse waves .2. hydrodynamic impact craters. Experiments in Fluids 35, 520-532.

Grilli, S. T., M. Ioualalen, J. Asavanant, F. Shi, J. Kirby and P. Watts (2007). Source constraints and model simulation of the December 26, 2004, Indian Ocean tsunami. Journal of Waterway, Port, Coastal, and Ocean Engineering 133, 414-428.

Jiang, L. and P. H. LeBlond (1993). Numerical 
modeling of an underwater Bingham plastic mudslide and the waves which it generates. Journal of Geophysical Research 98(C6), 10303-10317.

Kafle, J. (2014). Dynamic Interaction Between a Two-phase Submarine Landslide and a Fluid Reservoir, M. Phil. thesis, School of Science, Kathmandu University, Dhulikhel, Nepal.

Kafle, J. (2019). Advanced Dynamic Simulations of Landslide Generated Tsunami, Submarine Mass Movement and Obstacle Interaction. Ph. D. thesis, School of Science, Kathmandu University, Kavre, Nepal.

Kafle, J. and B. M. Tuladhar (2018). Landslidewater interaction for partially submerged landslide. Journal of Nepal Mathematical Society 1(1), 22-29.

Kafle, J. and P. Kattel (2019). Simulations for rotational symmetry through r.avaflow in the general two-phase mass flow model. Journal of Nepal Mathematical Society 2(2), 45-60.

Kafle, J., P. Kattel, M. Mergili, J.-T. Fischer and S. P. Pudasaini (2019). Dynamic response of submarine obstacles to two-phase landslide and tsunami impact on reservoirs. Acta Mechanica 230(9), 3143-3169.

Kafle, J., P. R. Pokhrel, K. B. Khattri, P. Kattel, B. M. Tuladhar and S. P. Pudasaini (2016). Submarine landslide and particle transport in mountain lakes, reservoirs and hydraulic plants. Annals of Glaciology 57(71), 232- 244.

Kattel, P. (2014). Dynamics of Quasi-Three Dimensional and Two Phase Mass Flows, M. Phil. thesis, School of Science, Kathmandu University, Dhulikhel, Nepal.

Kattel, P. (2019). Some Aspects of Multi-Phase Debris Flows: Dynamics, FlowObstacleInteractions and Model Construction. $\mathrm{Ph}$. D. thesis, School of Science, Kathmandu University, Kavre, Nepal.

Kattel, P., J. Kafle, J. T. Fischer, M. Mergili, B. M. Tuladhar and S. P. Pudasaini (2018). Interaction of two-phase debris flow with obstacles. Engineering Geology 242, 197-217.

Kattel, P., K. B. Khattri, P. R. Pokhrel, J. Kafle, B. M. Tuladhar and S. P. Pudasaini (2016). Simulating glacial lake outburst floods with a two-phase mass flow model. Annals of Glaciology 57(71), 349-358.

Khattri, K. B. and S. P. Pudasaini (2018). An extended quasi two-phase mass flow model. International Journal of Non-Linear Mechanics 106, 205-222.

Kuswandi and R. Triatmadja (2019). The use of dam break model to simulate tsunami runup and scouring around a vertical cylinder. Journal of Applied Fluid Mechanics 12(5), 1395-1406.

Ma, G., F. Shi and J. T. Kirby (2012). Shockcapturing non-hydrostatic model for fully dispersive surface wave processes. Ocean Modelling 43, 22-35.

Ma, G., J. T. Kirby, T. J. Hsu and F. Shi (2015). A two-layer granular landslide model for tsunami wave generation: theory and computation. Ocean Modelling 93, 40-55.

Masson, D. G., C. B. Harbitz, R. B. Wynn, G. Pedersen and F. Lovholt (2006). Submarine landslides: Processes, triggers and hazard prediction. Philosophical Transactions of the Royal Society A 364, 2009-2039.

Mergili, M., A. Emmer, A. Juricova, A. Cochachin, J.-T. Fischer, C. Huggel and S. P. Pudasaini (2018). How well can we simulate complex hydro-geomorphic process chains? The 2012 multi-lake outburst flood in the Santa Cruz Valley (Cordillera Blanca, Peru). Earth Surface Processes and Landforms 43, 1373-1378.

Mergili, M., J. T. Fischer, J. Krenn and S. P. Pudasaini (2017). r.avaflow v1, an advanced open-source computational framework for the propagation and interaction of two-phase mass flows. Geoscientific Model Development 10(2), $553-569$.

Miao, H., G. Wang, K. Yin, T. Kamai and Y. Li (2014). Mechanism of the slow-moving landslides in Jurassic Red-strata in the Three Gorges Reservoir, China. Engineering Geology.

Mohammed, F. and H. M. Fritz (2012). Physical modeling of tsunamis generated by threedimensional deformable granular landslides. Journal of Geophysical Research 117(C11015), 705-718.

Pitman, E. B. and L. Le (2005). A two-fluid model for avalanche and debris flows. Philosophical Transactions of the Royal Society A 363(3), 1573-1601.

Pokhrel, P. R. and S. P. Pudasaini (2020). Stream function-vorticity formulation of mixture mass flow. International Journal of Non-Linear Mechanics 121, 103317.

Pokhrel, P. R., K. B. Khattri, B. M. Tuladhar and S. P. Pudasaini (2018). A generalized quasi twophase bulk mixture model for mass flow. International Journal of Non-Linear Mechanics 99, 229-239.

Pudasaini, S. P. (2012). A general two-phase debris flow model. Journal of Geophysical Research 117(F03010).

Pudasaini, S. P. (2014). Dynamics of submarine debris flow and tsunami. Acta Mechanica 225(8), 2423-2434.

Pudasaini, S. P. and K. Hutter (2007). Avalanche Dynamics: Dynamics of Rapid Flows of Dense Granular Avalanches. Berlin, New York: Springer.

Qiao, C., G. Ou and H. Pan (2018). Numerical modelling of the long run out character of 2015 Shenzhen landslide with a general two-phase 
J. Kafle et al. / JAFM, Vol. 14, No. 3, pp. 861-876, 2021.

mass flow model. Bulletin of Engineering Geology and the Environment.

Sammarco, P. and E. Renzi (2008). Landslide tsunamis propagating along a plane beach. Journal of Fluid Mechanics 598, 107-119.

Shrestha, A. B., M. Eriksson, P. Mool, P. Ghimire, B. Mishra and N. R. Khanal (2010). Glacial lake outburst food risk assessment of sun Koshi Basin, Nepal. Geomatics Natural Hazards and Risk 1(2), 157- 169.

Slingerl, R. L. and B. Voight (1979). Occurrences, properties, and predictive models of landslidegenerated water waves. Elsevier Scientific Publishing Company, 317-394.
Viroulet, S., D. C'ebron, O. Kimmoun and C. Kharif (2013). Shallow water waves generated by subaerial solid landslides. Geophysical Journal International 193, 747-762.

von Hardenberg, W. G. (2011). Expecting disaster: The 1963 landslide of the Vajont dam. Environment and Society Portal, Arcadia 8.

Walder, J. S., P. Watts, O. E. Sorensen and K. Janssen (2003). Tsunamis generated by subaerial mass flows. Journal of Geophysical Research 108(5), 2236-2255.

Ward, S. N. and S. Day (2011). The 1963 landslide and flood at Vajont Reservoir Italy, a tsunami ball simulation. Ital. J. Geosci. 130(1), 16-26. 